\title{
THE DOCUMENTATION AND PROTECTION OF CULTURAL HERITAGE DURING EMERGENCIES
}

\author{
F. J. Rufián Fdez. ${ }^{1, *}$, M. Fernández Díaz ${ }^{2}$, I. Sabrine ${ }^{1,3}$, J. J. Ibáñez ${ }^{3}$, B. Claramunt-López ${ }^{4,} 5$, A. Escobar ${ }^{4}$, J.A. González \\ Zarandona ${ }^{6,7}$ \\ ${ }^{1}$ Heritage for peace - francisco.rufian@gmail.com \\ ${ }^{2}$ Virtua Nostrum - info@virtuanostrum.com \\ ${ }^{3}$ Institución Milá y Fontanals (CSIC) - (isber.sabrine, ibanezjj)@imf.csic.es \\ ${ }^{4}$ CREAF - (bernat, a.escobar)@ creaf.uab.cat \\ ${ }^{5}$ BABVE-UAB \\ ${ }^{6}$ Columbia University \\ ${ }^{7}$ Alfred Deakin Institute for Citizen and Globalization - antonio.g@deakin.edu.au
}

Commission II - WG II/8

KEYWORDS: Photogrammetry, Emergency, Heritage, Documentation, Resilience, Civil Society, Social Engagement, Citizen Science

\begin{abstract}
:
This paper aims to highlight the importance of fast and safe documentation of the damage to cultural heritage after a natural or anthropic catastrophe, with greater relevance of civil society. In these situations, in which humanitarian aid to the population and care needs are the priorities for the local authorities, proper prior planning of data collection and their transmission may aid faster and better decision-making in an emergency. New technologies are among the most effective tools to carry out such damage assessments actions. Therefore, we are currently establishing adequate planning and training of the local civil society, through projects that aim to achieve specific goals, enhancing their capacity to protect heritage, and improving the resilience of the inhabitants after disasters. Most heritage projects that work towards the recovery and conservation of heritage after an emergency occurred do not consider the local population. Therefore, in this paper we offer an approach for heritage workers in the hope that by including the local population, the documentation of heritage destruction can lead to better methods in the future.
\end{abstract}

\section{DOCUMENTATION OF HERITAGE DURING EMERGENCY}

The use of new technologies has grown exponentially, permeating every aspect of our lives. It has consequently also affected the way in which different communities around the world experience heritage, whether their own or that of other cultures. People are increasingly encountering sites and monuments and learning about the past through digital media, in the form of virtual reconstructions, digital representation of artifacts, online videos, among others. This advance is particularly striking in the case of younger generations, for which the first experience of cultural heritage is often through a digital surrogate that shapes their understanding and perception (Economou, 2015).

And, as Professor Sudharsahan Seneviratne said in the award acceptance speech of Conservation and Heritage Management Award for Excellence in 2013: "The next generation essentially needs to grasp the dialectics of "present in the past and past in the present' as the very foundation of the humanistic heritage professional".

In connection, the past few years have seen many developments in the documentation of architectural and archaeological sites through low-cost methodologies, mainly using freeware and open-source initiatives, which have demonstrated their usefulness in many projects ${ }^{1}$. However, prior knowledge of action planning and preparations before the emergencies are nor usually carried out, and this is the key to improve the adaptation and response capacity to emergencies and disasters.

\footnotetext{
* Corresponding author

For more information please refer to bibliography.
}

The management models of heritage sites should look at the prevention plans by improving their capacity in rapid responses in emergencies. However, this is impossible without the correct training, not only of professionals (either locals or belonging to foreign entities), but also of the inhabitants of the area. Moreover, this training must be focused on complex forms of decision-making before and after the emergency, and they need technological support for achieving the objective of reducing risk (Antofine, 2020).

The variety of current techniques provides us with a wide range of possibilities when carrying out documentation. They depend on the characteristics of the site, the needs to cover the costs, the time, the complexity, and/or the size of the object itself; and on the accessibility and the skills of the involved participants. Teams must be able to decide which techniques to use and how they will be implemented, to ensure that the objectives are met quickly, cheaply and, above all, guaranteeing the safety of the working team at all times.

However, a single documentation methodology may not guarantee the desired accuracy because each technique is limited and sometimes very specific; consequently, a combination of different techniques to achieve the desired results is needed in most cases. For example, if the objective is to document a large archaeological site, accurately and quickly, it is possible to use a commercial drone. However, if the objective is to add definition to a photogrammetric survey and include interior or underground parts, it is best to combine the use of drones with terrestrial cameras (DSLR, compact cameras and even mobile phones) (Figure 1). Of course, to document archaeological pieces, only terrestrial devices are needed (Figure 2). 


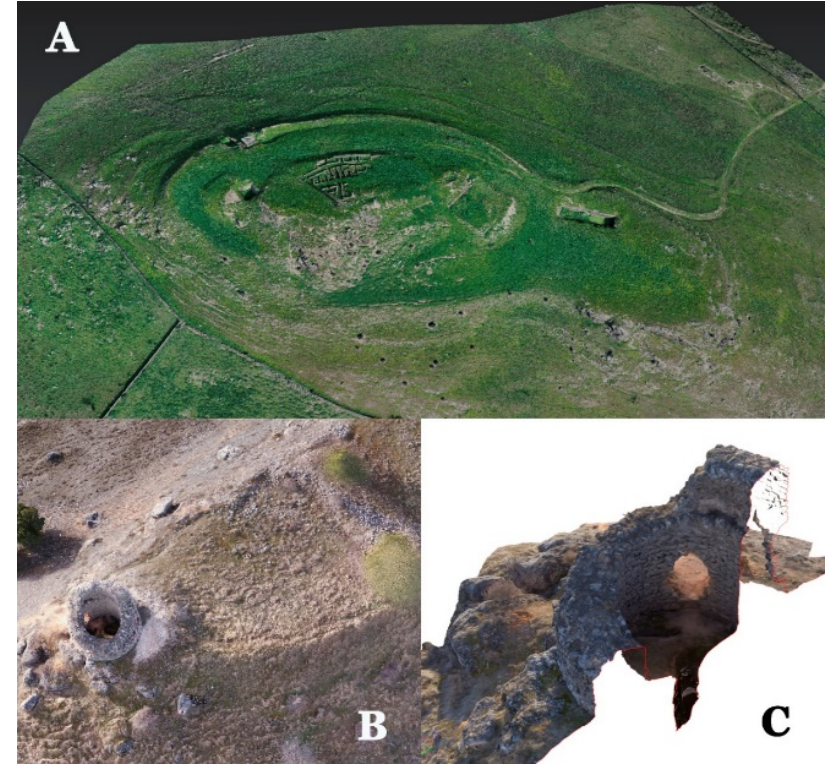

Figure 1. A. 3D model made with RPAS/drone of Hornachuelos Iron Age hillfort (17 hectares, Spain); B. 3D model of a medieval tower (Membrillera Spain), made with a drone and compact camera to document the interior and underground parts; C. Cross-section over a 3D model of Membrillera tower.

Therefore, the documentation process must be studied and planned in advance, since the strategy and documentation for a cultural asset that is already studied and of which there is enough data, is entirely different of another that has never been considered. In the first case, when the cultural asset is well known, it will be sought to have an accurate and rapid knowledge of the damages suffered, in order to make the right decisions in the shortest possible time to avoid deterioration and plan for their recovery. In the second case, when we do not know the cultural asset ${ }^{2}$, the information that is collected must be much more extensive, and therefore, will require more extensive work, and of greater depth, e.g. having to look for previous documentation of other interventions.

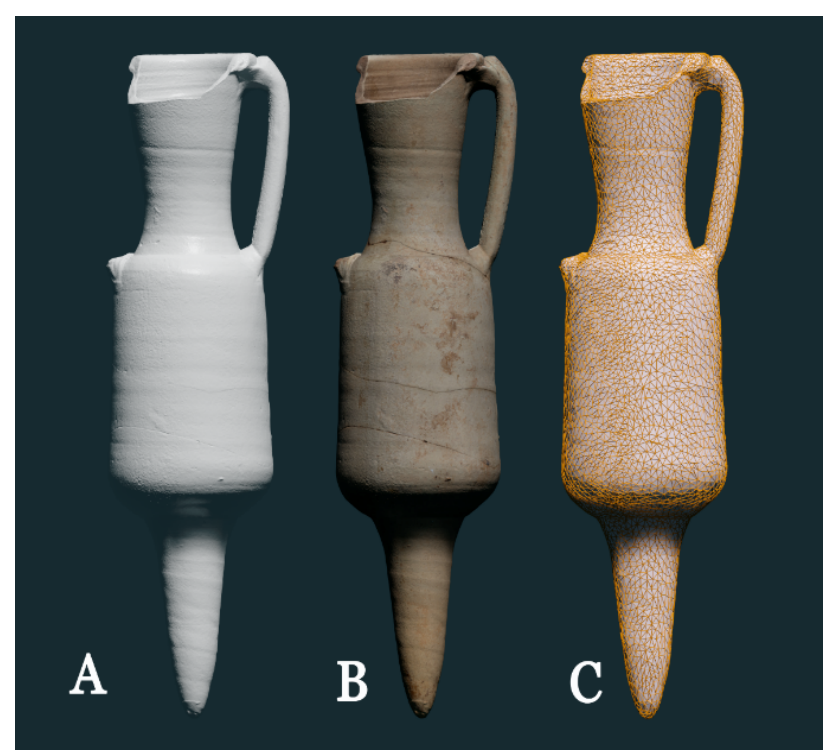

Figure 2. Different representations of a digitized Roman amphora with photogrammetry. A. High-resolution mesh; B. Low-poly mesh with high-resolution textures; C. Low-poly wireframe.

2 "The looters themselves are discovering ancient cities, that scholars did not yet know where they were" Manuel Molina

https://elpais.com/cultura/2017/02/24/actualidad/1487929375_263952.html
Our working hypothesis considers integrating a multidisciplinary vision to define the pros and cons of the inclusion of the civil society during the first steps after an emergency and defining what can be improved for the recovery and return to a normal situation.

Through two projects, that are currently in execution, we aim at improving the effectiveness of such actions, by training the locals, both in documentation techniques, as noted above, and in the first interventions avoiding significant losses and curbing damages; and in the dissemination of work, involving the local civil society as a whole. In that way, and through the pursuit the development of cultural heritage, we are seeking a comprehensive development in the countries ${ }^{3}$ that meets their needs and achieves higher levels of socioeconomic development.

In summary, and based in our previous experience, we have considered that in an intervention on heritage sites, after a conflict or a catastrophe, in addition to technical interventions, at least the following objectives should be sought:

- Define primary intervention strategies focused on acting in emergencies of the cultural heritage at risk, which include and combine the training and preparation of local authorities and professionals.

- Identify and publicize the cultural heritage's values and how important its protection is.

- Encourage local communities to work in a way that integrates the protection of the local cultural heritage as part of the development of the region.

- An updated database of damages and risks to cultural heritage, to help define the most urgent actions, and their qualification. The database should register past activities and their consequences, so it could be used to learn from past situations.

- Create multidisciplinary work teams, involving a local leader, who would guarantee the sustainability after the project, and would train more participants.

- Understand how data on damages, risks, and needs collected during first aid to cultural heritage can be used to promote early recovery of the affected cultural and its associated communities.

We think that it is compulsory to involve the local people to (a) improve the results of low-cost documentation methodology after any kind of disasters, and (b) to ensure the implementation of urgent measures that guarantee the protection and development of cultural heritage.

\section{THE ROLE OF CIVIL SOCIETY ORGANISATIONS}

Right as a first step designing the projects, we have taken into account the principle that heritage must be studied and preserved in a direct connection with the people/community of its origin (Archibald, 2005). Therefore, the first aim, that we wanted with the projects, was to analyze how digital technologies can aid not only in heritage documentation and conservation but also in the development of the region. And involving local people in the project through specific training should be the primary way in which we could improve recovery capacities of their community and help them to plan effective response methods that could mitigate possible future damage.

These counties are Syria, Yemen, Iraq, and Libya. 
The final objective is to promote the economic and social development, based on heritage as a sustainable resource, but, as stated above, understood with the active participation of the local communities, both in the design, execution and subsequent development. Inclusive growth must be guaranteed in compliance with fundamental ethical principles, in order to guarantee the rights of locals, something that will be completely necessary for the context of increasing growth and opportunities for the regions.

However, this growth has not traditionally resulted in a positive impact for all the societal actors, especially when rising inequalities (due to class, gender or living conditions), ongoing tensions and conflict between different countries and communities (for religious, ethnic, political or other reasons) are continuously increasing. Subsequently, there is a need for new approaches that respond to social and economic challenges and also build on local assets that increase opportunities for inclusive growth.

Local cultural heritage is a valuable tool to foster a sense of pride and working out how to "show it off is important as the conservation works" (Grimwade, Carter, 2000). The engagement of civil society through local communities in cultural heritage management is a fundamental component of human rights in society. It is impossible to separate a people's cultural heritage from the people itself and that people's rights (Bennoune, 2016).

In connection with the role of civil society, the actions designed for heritage recovery, and the works directed to its documentation, need to consider the relations of the heritage sites with their surroundings. They may allow us to use traditional cultural practices, that local communities perfectly know, and would improve the relationship between the inhabitants and their heritage, thriving in the dangerous and challenging moments that these regions are currently living.

Besides, it allows us to involve sectors of the society that are traditionally left out of this type of initiatives, like women and young people, in most cases the first to be affected by war. Moreover, they may (re-)discover their own culture, having a positive force both for social reconstruction and cohesion and for eventual reconciliation (Almagro et al., 2015).

Whereas heritage can, and often do, bind a person or group to a country, religion, and culture through a shared and collective experience (Anderson, 1983), the recovery process after a conflict needs to be conducted most of the times correctly, looking for a kind of reconciliation. It is essential to raise awareness through talks and visits that involve local authorities, emphasizing that sustainably managed heritage is a fundamental economic and social resource that can help in the regeneration of the area. This may also act as a peace discourse that unites the people in opposition to reactionary discourses that seek to divide rather than unite, and in many cases weaponizing heritage, such as those by the so-called Islamic State (Isakhan, González Zarandona, 2018).

The project will contribute to a new development in the relationship between international experts and local professionals, which will also be transmitted to the communities of the area, seeking a renewal effect on the vision and attitude of the inhabitants towards their heritage.

The only possible way to ensure the long-term preservation of heritage sites in the most appropriate way is to keep them as an active part of the community. Reintegrating them into the daily life of the population, from which they have formed over the centuries, their hallmarks as a community, and with which they feel identified, are essential pillars in the coexistence and daily life of the population. That is the reason emergency volunteerism offers longer-term opportunities for more structured citizen response through training and creation of response teams (Poljansek, 2017).

The interventions should transversely work to facilitate the return to the traditional spaces, loaded with symbolism to their communities, so they may become new cultural and leisure places where citizens will enjoy the city and urban fabrics while sustainably integrating their past and future. The recovery of a heritage asset cannot be fully understood if it is not done from the social fabric where it is located, nor without its participation since it is within it where its essence is recognized, and where it has its real meaning.

\section{THE PROJECTS}

Projects ideas arose thanks to the previous work of the team, in contact with the people who are currently working in Syria and other countries in conflict. Local inhabitants transmitted us a series of needs and weaknesses that are continually repeated in the intervention works that have been carried out. Therefore, an interdisciplinary scientific team was created to promote the exchange and understanding of research, ideas, projects, and other related aspects that characterize interventions in cultural heritage and with the local communities. The implementation is being performed through the following projects:

\subsection{The protection of heritage in conflict zones through digital tools: the role of civil society.}

The project aims to use digital tools to support NGOs and local organizations, to develop databases on heritage assets in danger, focusing on countries affected by armed conflicts such as Syria, Yemen, Iraq and Libya.

Through registration and documentation techniques, based on an App, which will be developed exclusively for this function, we will (i) improve protection against looting and/or vandalism; and (ii) permanently document time and place of the pieces that may enter the illicit traffic of cultural property.

The App will include information to identify the pieces following Object ID $^{4}$ criteria. The smartphone app is built by prioritizing the safety of the user, encrypting all the information and leaving no trace of the information in the user's smartphone once it is sent to the central database managed by Instituto Milá I Fontanals in Spain. In this way:

- The involvement of civil society in heritage protection will be enhanced.

- The use of digital tools in the Humanities will be deepened.

- A new heritage protection methodology will be developed during conflicts that will open future fields of action.

- The role of innovation and social transformation provided by the Humanities will become more evident before society and policymakers.

\footnotetext{
The international standard that describes cultural property, facilitating its identification in case of theft. http://archives.icom.museum/object-id/index.html
} 
The ability of mobile phones to be used in different conditions and in a safe environment ${ }^{5}$ for the users opens up new possibilities for the communication of the heritage sites in danger, to support engagement and learning at different levels, as well as establishing a link between the heritage organization and its users that can be shared with internationals police departments. Apart from this one-to-one connection, the natural use of social networking via mobile devices also allows for the creation of communities and networking among diverse user groups themselves (Economou, 2015).

\subsection{Documentation and protection of cultural heritage in the province of Raqqa (Syria).}

As a continuation of the previous project, this one is focused on creating multidisciplinary work teams to train the Syrian heritage professionals in the documentation of the damage to archaeological sites, monuments and warehouses belonging to the archaeological missions. The documentation will be carried out with a methodology that guarantees speed and safety, using terrestrial photogrammetry with support from Drones / RPAS. Also, training in emergency interventions is contemplated to prevent the loss of cultural property (Figure 3 ).

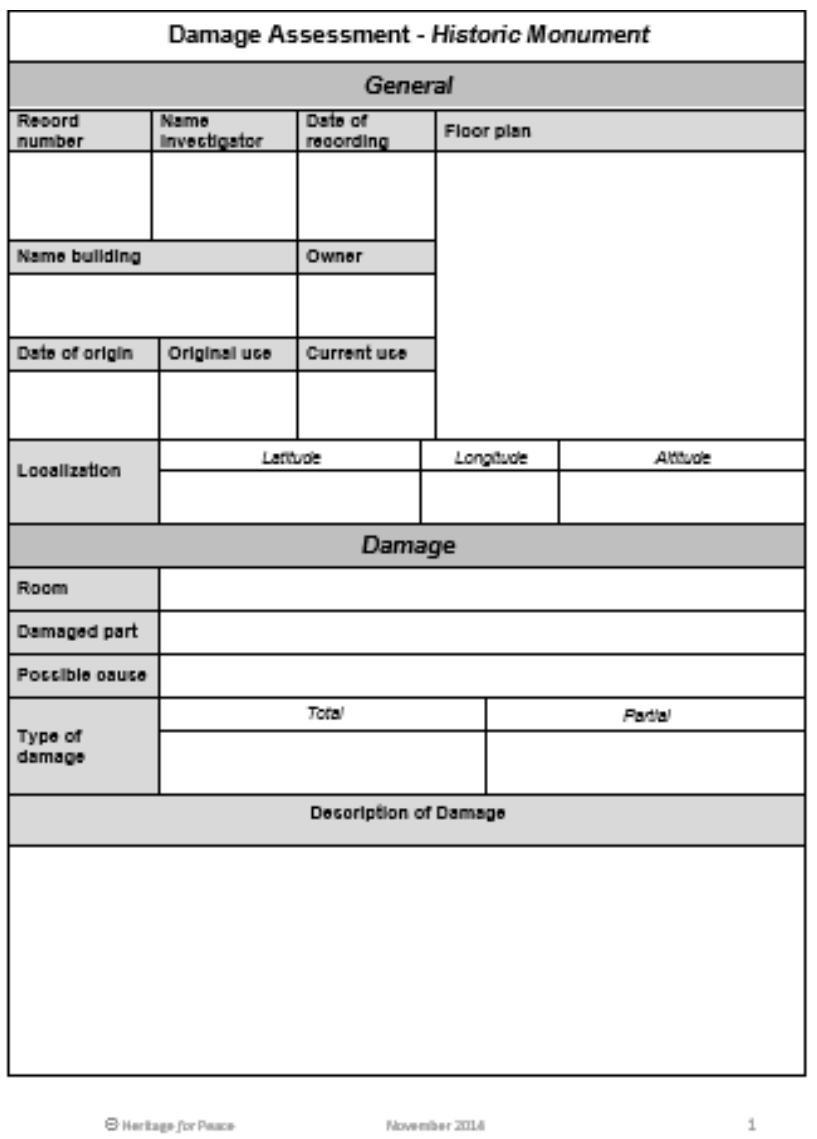

Figure 3. Example of Damage Assessment Sheet used by Heritage for Peace in previous training.

Likewise, we also have the support of Authority of Culture in SelfManagement in North and East Syria (ACNES), - an administrative entity that manages the cultural heritage of the North East in Syria, formed by a series of professionals who are currently working with the authorities of the region.
In doing so, we can guarantee that the local peculiarities of the Raqqa population will be considered during the collection and analysis of data.

The local community members of ACNES will receive the training in cultural heritage protection by international experts from the Spanish National Research Council (CSIC -IMF), Heritage for Peace (a leading NGO in the protection of Syria's cultural heritage), CREAF (a public research centre dedicated to terrestrial ecology, territorial analysis and global change) and Rahabimed (an interdisciplinary network of the Mediterranean aimed at sustainable rehabilitation, heritage restoration and urban regeneration).

The Members of ACNES will be responsible for the documentation of the damage caused by destruction to the regions' tangible cultural heritage in the ground. Integrated techniques and information management, together with active stakeholder participation, are going to be used as conservation and management tools.

We have rejected the use of a laser scanner in the project, due to its large size. Other limitations of laser scanners include their limited use only in small interior spaces, and they need skilled operators, and long post-processing time (Hassani, 2015). Therefore, we have decided to use mainly low-cost digital photogrammetry in the project. That allows professionals to commit to the objectives of the project and learn to use it in an affordable time (Shults et al., 2017; Wojciechowska, Łuczak, 2018). In the past, the use of other technologies has restricted its use to institutions and companies with sufficient capital and resources to use them.

Digital photogrammetry can significantly reduce the time devoted to the development of documentation and conservation plans, and it is a tool that allows us to implement our job in virtually any site, more efficiently, and at a much lower cost. In Syria, where we do not have the necessary funding or equipment to carry out this work, these techniques will increase their capacity to work. Also, the photogrammetry will be used for raising awareness through local communities

The models created can be used to provide the conservator with a visual reference of the different pathologies to be considered to plan the intervention. From de threedimensional model, we could obtain other very useful products for scientific analysis and damage assessment. Then, it is possible to analyze other points of view from computer equipment, observing a site as a whole, in which new data not visible on the ground can be recorded (Figure 4). Besides, it is possible to integrate new objects into the model to show which responses can be better than others, as well as integrate the $3 \mathrm{D}$ models and the products generated with the digitization, into databases and other software used for remote sensing and analysis of archaeological data (like Geographic Information Systems or CAD) (Figure 5).

Based on an archaeological site 3D model, heritage professionals can create high-resolution orthoimages of sites and buildings in order to identify damages, pathologies or looting pits (Figure 6), and they can generate Digital Terrain Models (DTM) or Digital Elevation Models (DEM) and a lot of digital products that are useful for inaccurate identification of new elements unable to registry in situ.

\footnotetext{
The information is automatically erased in the mobile after sending it.
} 


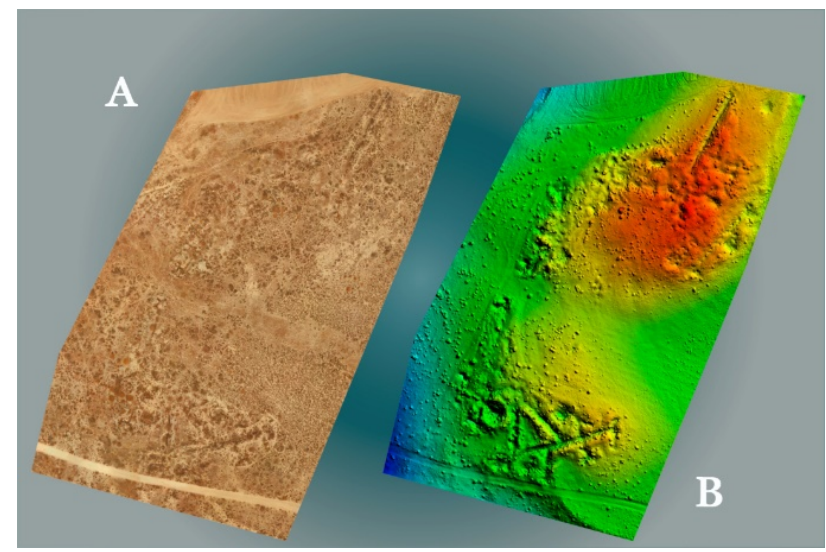

Figure 4. Remote sensing of Spanish Civil War structures with drone. A. High-resolution orthoimage; B. Visualization of trenches, shelters and artillery impacts using a Digital Elevation Model

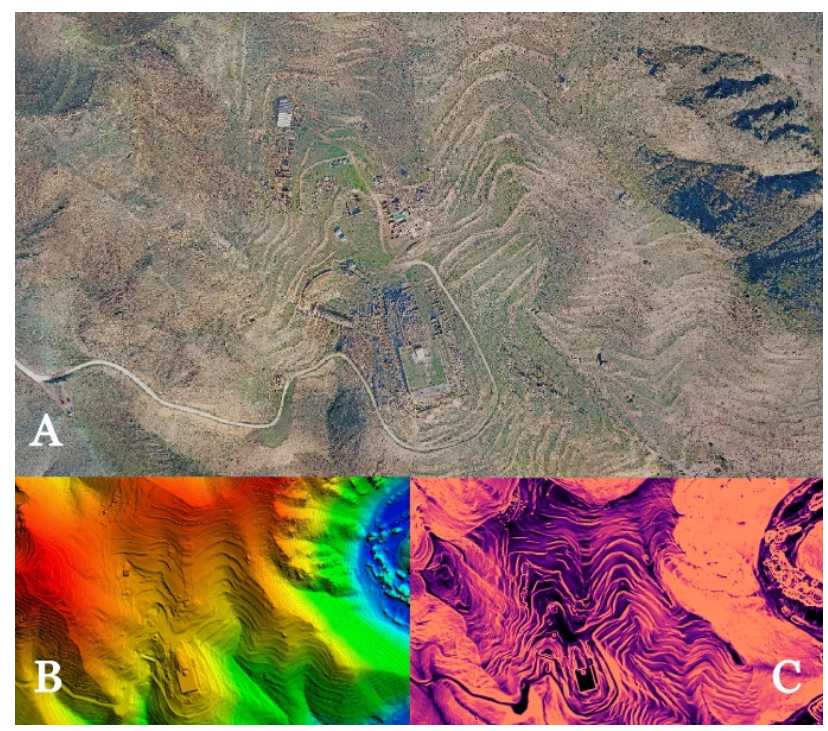

Figure 5. Photogrammetric survey made with RPAS/drone over a Roman archaeological site (40 hectares).

A. High-resolution orthoimage integrated into GIS software; B. Digital Elevation Model with level curves as a GIS layer;

C. Slope analysis with GIS, aimed at recording the terrace system and studying erosion and other damages

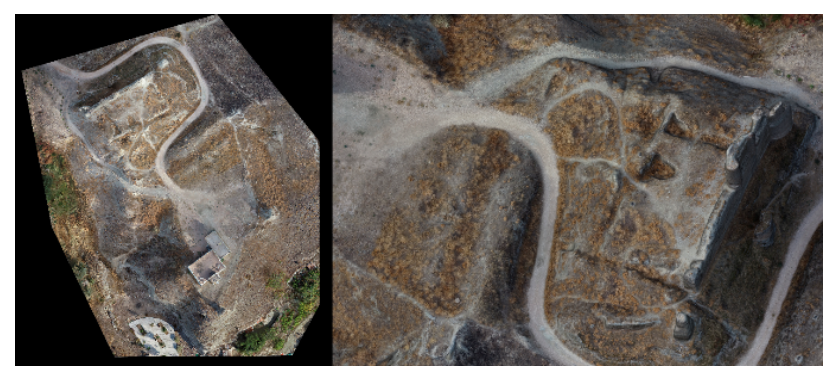

Figure 6. Photogrammetric survey made with RPAS/drone over the medieval castle of Fuentidueña (Spain). On the left: highresolution orthoimage. On the right: 3D model. This survey was done with the aim of identifying damages, erosion, walls pathologies and looting pits

\section{DATABASES, RECOVERY AND EMERGENCY PLANS}

The work carried out in the fields related to the recovery of heritage must be conveniently registered in digital databases, so it can be accessible to professionals and the general public, enabling the generation of a new intervention or dissemination projects.

Systematically collected, comparable and robust disaster damage data are an essential element of the risk assessment and management processes (Ríos, 2018). The aim is to design a specific digital database focused on recording and studing heritage, inspired in previous examples that are currently working, two of which are:

- Desinventar ${ }^{6}$ : Online and collaborative database developed by the United Nations Office for Disaster Risk Reduction (see Figure 7).

- Antiquities Trafficking: Maps Take Aim at Looters and Buyer $^{7}$ : Geographical Information System created by The Antiquities Coalition and Esri to combat against illicit trafficking in antiquities.

The development of long-term risk prevention plans could be another possibility aimed at reducing the vulnerability of the population, and/or at minimizing the damages that could be caused by natural or anthropic threats. These databases will allow a better understanding of the strategic resources, the choice of optimal and rapid evacuation routes, the location of supply centers, a list of civil organizations with adequate training in the affected area, etc. The created plans will be updatable, helping to rationalise and make the disaster response faster.

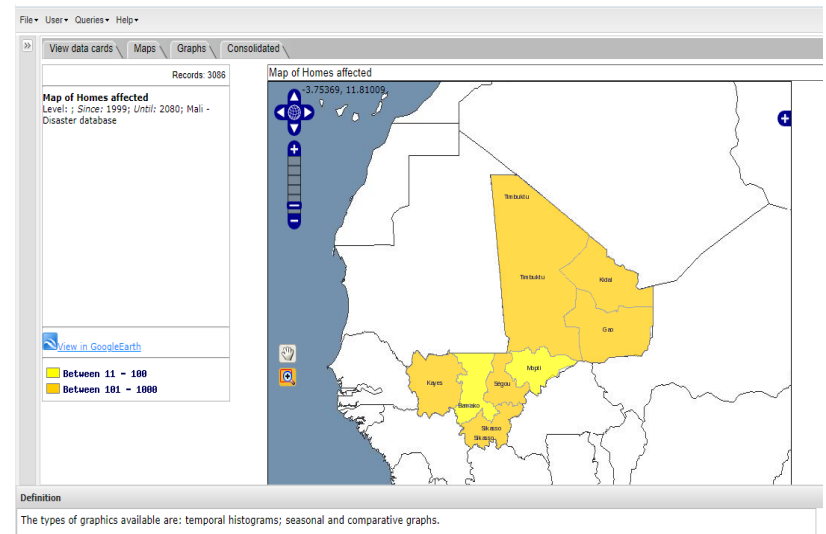

Figure 7. Example of homes affected in a catastrophe. from https://www.desinventar.org

The cultural and natural heritage itself can contribute to reduce the effects of disasters in various ways, e.g., traditional knowledge integrated into the construction and planning of the territory, or ecology-based and local management systems can not only prevent or mitigate the impact of disasters but also offer mechanisms that serve to cope with post-disaster situations.

\footnotetext{
https://www.desinventar.org

https://www.esri.com/about/newsroom/blog/maps-take-aim-atantiquities-looters/
} 
Disasters can have serious financial consequences, and it is much cheaper to invest in risk management planning in disaster prevention than to spend large amounts on recovery and rehabilitation after disasters.

In summary, reflecting such knowledge in appropriate databases, and in protection plans, can help heritage play a more active role in the recovery and rehabilitation. Following the UNESCO Managing Disaster Risks for World Heritage reference manual, the following needs have to be taken into account:

- Using traditional skills, experience and capabilities for rehabilitation after a disaster.

- Studying the mode, livelihoods and technologies that should be used in the reconstruction. In this respect, much can be learned from mistakes made in the past.

- Recognizing that cultural and natural heritage is a source of identity that can contribute to the psychological recovery of disaster victims.

- Using local mechanisms to deal with disasters through traditional social networks to promote recovery.

\section{CONCLUSIONS}

Any activity related to heritage and society must (i) take into account similar programs and events from the beginning, (ii) evaluate all processes that allow continuous learning, and (iii) detect failures and weaknesses within the shortest possible time. To support the economic well-being of the population, for example, we need to provide strategies for cultural tourism.

Culture is an essential factor for peace and stability of the society and constitutes the values that give meaning to the community and their identity. Culture in all its manifestations is an essential instrument in addressing the objectives of peacebuilding after conflicts and disasters. Therefore, including the civil society is vital to ensure that the goals are realistic and relevant to the needs of communities.

\section{REFERENCES}

Almagro Vidal, A., Tandon, B., Eppich, R., 2015. First aid to cultural heritage. Training initiatives on rapid documentation. Int. Arch. Photogramm. Remote Sens. Spatial Inf. Sci., XL5/W7, 13- 19, https://doi.org/10.5194/isprsarchives-XL-5-W713-2015 (20 January 2020).

Anderson, Benedict R. O'G. 1983. Imagined communities: reflections on the origin and spread of nationalism (Revised and extended. ed.). London: Verso. ISBN 978-0-86091-546

Antofie, E., Marin Ferrer, M., Luoni, S., Eklund, G., 2020. Decision Making Improvement for Disaster Risk Management (DRM) through technological support. DRMKC Risk Data Hub, GRRASP (Geospatial Risk and Resilience Assessment Platform) and RAPID$N$ (Rapid Natech Risk Analysis and Mapping System) 3rd DRMKC RDH Workshop, 16th of October 2019. JRC Technical Report: http://dx.doi.org/10.2760/44907 (10 April 2020)

Archibald, R., 2005. The New Town Square; Museums and Communities in Transition. The Annals of Iowa 64, 292294.https://doi.org/10.17077/0003-4827.10933 (27 October 2019)
Bennoune, K., 2016. Cultural heritage is a human rights issue, UNESCO: http://en.unesco.org/news/karima-bennoune-culturalheritage-human-rights-issue (20 March 2020).

British Council. 2018. Cultural Heritage for Inclusive Growth. www.britishcouncil.org/sites/default/files/bc chig report final. pdf_(26 March 2020).

Domínguez I. 2017 Los saqueos destruyen para siempre ciudades milenarias de Iraq y Siria. El País https://elpais.com/cultura/2017/02/24/actualidad/1487929375 2 63952.html_(13 April 2020).

Economou, M. 2015. Heritage in the Digital Age. 10.1002/9781118486634.ch15. (26 October 2019).

Grimwade, G., and Carter, B. 2000. Managing Small Heritage Sites with Interpretation and Community Involvement, International Journal of Heritage Studies 6:1, 33-48.

Hassani, F., 2015. Documentation of cultural heritage; techniques, potentials, and constraints. Int. Arch. Photogramm. Remote Sens. Spatial Inf. Sci., XL-5/W7, 207-214, https://doi.org/10.5194/isprsarchives-XL-5-W7-207-2015 (27 October 2019).

Isakhan, B. and González Zarandona, J. A. 2018. Layers of religious and political iconoclasm under the Islamic State: symbolic sectarianism and pre-monotheistic iconoclasm. International Journal of Heritage Studies, 24:1, 1-16, DOI: 10.1080/13527258.2017.1325769.

Lambert, S., Rockwell, C., (Eds.), 2012. Protecting Cultural Heritage in Times of Conflict: Contributions from the participants of the International course on First Aid to Cultural Heritage in Times of Conflict. ICCROM. https://www.iccrom.org/sites/default/files/ICCROM_18_Protect ingHeritageConflict_en.pdf (26 October 2019).

Lowe, T.M., 2013. Cultural Heritage as a Tool for Development and Diplomacy: Examining further uses of UNESCO's intangible heritage-based Socioeconomic Development programs for Women., The State University of New Jersey, USA. rucore.libraries.rutgers.edu/rutgers-lib/41856/PDF/1/play/ (25 October 2019).

Poljansek, K., Marín Ferrer, M., De Groeve, T., Clark, I. (Eds.), 2017. Science for disaster risk management 2017: knowing better and losing less. Publications Office of the European Union, Luxembourg, http://dx.doi.org/10.2788/842809 (9 April 2020).

Ríos Díaz, F., Marín Ferrer, M. 2018. Loss database architecture for disaster risk management. Publications Office of the European Union, Luxembourg http://dx.doi.org/10.2760/647488 (10 April 2020).

Schneider, P., (Ed.), 2017. Catastrophe and challenge cultural heritage in post-conflict recovery. Brandenburgische Technische Universität Cottbus-Senftenberg IKMZ-Universitätsbibliothek. https://opus4.kobv.de/opus4btu/frontdoor/index/index/docId/43 73 (26 October 2019).

Shults, R., Krelshtein, P., Kravchenko, I., Rogoza, O., Kyselov, O., 2017. Low-cost Photogrammetry for Culture Heritage. Environmental Engineering 10th International Conference. Vilnius Gediminas Technical University. Lithuania, 27-28 April 2017. doi.org/10.3846/enviro.2017.237 (9 March 2020). 
Sudharshan, S. Humanising Archaeology in Multi-cultural Society. - award acceptance speech, Conservation and Heritage Management Award for Excellence 2013, Archaeological Institute of America. The Sunday Times, Sri Lanka, Comments, 24 March 2013. https://www.pressreader.com/sri-lanka/sundaytimes-sri-lanka/20130324/282346857257621 (25 October 2019).

UNESCO, 2014. Reference Manual. Managing Disaster Risks for World Heritage. https://whc.unesco.org/en/managingdisaster-risks/ (24 October 2019).

Vileikis, O., Cesaro, G., Santana Quintero, M., van Balen, K., Paolini, A., Vafadari, A., 2012. Documentation in World Heritage conservation: Towards managing and mitigating change - the case studies of Petra and the Silk Roads. Journal of Cultural Heritage Management and Sustainable

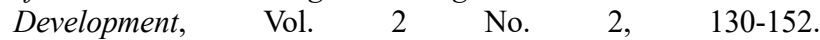
Https://doi.org/10.1108/20441261211273635 (25 October 2019).

Waas, M., Zell D., 2013. Practical 3D photogrammetry for the conservation and documentation of Cultural Heritage. International Conference on Cultural Heritage and New Technologies. Vienna. https://www.chnt.at/wpcontent/uploads/Waas_Zell_2014.pdf(24 October 2019).

Wojciechowska, G., Łuczak, J., 2018. Use of close-range photogrammetry and UAV in documentation of architecture monuments. XVIII Conference of PhD Students and Young Scientists. doi.org/10.1051/e3sconf/20187100017 (9 March 2020). 